\title{
A Case Study in Generic Drug Use: Should There Be Risk Adjustment in Incentive Payments for the Use of Generic Medications?
}

\author{
Surrey M. Walton, PhD; Christine Rash, PharmD; Bruce L. Lambert, PhD; \\ and William L. Galanter, MD, PhD
}

\begin{abstract}
BACKGROUND: Encouraging generic drug use has reduced health care costs for payers and consumers, but the availability of therapeutically interchangeable medications or generic medications of choice is not equal across disease states. The extent to which systems of care are able to substitute with generics is not well understood.

OBJECTIVES: To (a) define and measure the maximum generic rate (MGR) of currently prescribed drugs within an academic medical group in and (b) illustrate differences across drugs associated with selected underlying diseases. METHODS: Prescription claims data were examined from an academic medical group in Chicago, Illinois. Based on pharmacologic and therapeutic criteria, drugs were classified into 2 categories-potentially substitutable and not potentially substitutable-based on whether the drugs are branded forms of the same chemical entities that are available as generics or are therapeutically interchangeable with other medications that have different chemical compositions but the same mechanisms of action and potential efficacy. A medication was considered potentially substitutable if it (a) did not have a narrow therapeutic index as defined by the FDA; (b) did not belong to 1 of 6 protected classes of drugs in the Medicare D provisions; (c) was substitutable with a generic medication containing the same chemical entity; or (d) was therapeutically interchangeable with a therapeutically equivalent medication. MGR was defined as the percentage of prescriptions that could potentially be prescribed in generic form. This rate was examined overall and across drugs known to be associated with illustrative diseases including hypertension, diabetes mellitus, and obstructive lung diseases.

RESULTS: The MGR ranged from $100 \%$ for drugs used in hypertension to $26.7 \%$ for drugs used in obstructive lung diseases. The MGR was $83.6 \%$. CONCLUSIONS: Payers wishing to promote generic substitution should incorporate the potential for substitution of clinically appropriate generic medications as part of incentives for generic utilization to avoid unintended consequences of using a fixed target rate. A practical methodology for determining an MGR is offered.
\end{abstract}

J Manag Care Pharm. 2014;20(11):1093-99

Copyright @ 2014, Academy of Managed Care Pharmacy. All rights reserved.

\section{What is already known about this subject}

Use of generic medications can reduce costs with potential savings estimates ranging around $\$ 300$ per patient without harming patients. Current incentives towards generic medication use tend to use a flat rate not conditional on the existing use of drugs or underlying patient population.

What this study adds

This study provides a method for generating target generic rates that control for the existing medications in use and, thereby, the underlying patient population.

This study provides novel estimates of the potential for generic substitution for groups of drugs associated with common conditions. ncouraging the use of generic drugs has helped reduce -1 costs and can continue to reduce health care costs for payers and consumers with a recent simulation estimate suggesting savings of close to $\$ 300$ per patient among Medicare Part D enrollees. ${ }^{1-4}$ Recent opportunities and related efforts to increase the use of generic drugs have been key driving factors moderating pharmacy cost trends over the past 5 years. ${ }^{5,6}$ Various health care payers have employed specific payment initiatives to drive down costs by incentivizing providers to increase the percentage of generic drugs used in their patient populations. ${ }^{4}$ Currently, payers often reward independent physician associations (IPAs), individual physicians, and accountable care organizations (ACOs) that show improved prescribing patterns in terms of approaching predetermined benchmarks for generic prescribing. Benchmarks for generic dispensing rates (GDR) are typically derived using formulas created by insurance companies on an annual basis based on past performance of "top performing" IPAs. ${ }^{7,8}$

One concern with strategies designed to achieve a flat-rate benchmark for generic utilization is that available treatments for some patient populations are branded only, such as insulin products for insulin-requiring patients with diabetes mellitus and asthma medications in the form of inhaler devices. Furthermore, the use of medical supplies (e.g., blood glucose monitors, glucose test strips, glucose testing lancets) tend to be branded only, and orders for such equipment often count as prescriptions under some payers' financial incentive measures. In addition, in certain clinical scenarios that require medications with a narrow therapeutic index (NTI), switching patients from brand to generic medication may be clinically inappropriate and potentially harmful (e.g., switching a patient on Tegretol tablets to carbamazepine tablets for management of seizure disorder). Hence, the prevalence of conditions being treated and pre-existing drug choices may have a significant impact on the overall ability for an IPA, ACO, or individual physician to achieve a particular percentage of generic use and therefore to reach the benchmark for financial incentive. For example, 1 study claimed that $87 \%$ of variation in generic prescription rates was due to differences in case-mix. ${ }^{9}$

To our knowledge, only 1 previous study has examined the maximum potential cost savings as a result of generic substitution. Kunisawa et al. (2013) examined 9 million dispensing records in Japan from January to March 2010 and defined maximum potential quantity-based shares as the quantity of generic drugs dispensed plus the quantity of branded drugs that could have been replaced by generic drugs divided by the quantity of all drugs dispensed. ${ }^{10}$ A "substitution index" was 
defined as the proportion of potentially substitutable drugs (brand-name medications that could have a generic alternative dispensed) that were actually prescribed as generic. Study results showed a maximum potential quantity-based share of $50.1 \%$ and a maximum possible cost savings of $16.5 \%$ with generic medications. ${ }^{10}$ Kunisawa et al. concluded that comparisons based on quantity-based share may misrepresent actual medication use, and a substitution index accounting for maximum potential quantity-based share may be a fairer measure and encourage more realistic goals for generic medication use. ${ }^{10}$

Payers commonly offer financial incentives to providers for achieving benchmark rates of generic drug use..$^{11,12}$ Providers and payers should understand the extent to which patient case mix affects the ability to prescribe generic medications. For example, if an IPA sees a high volume of patients with insulindependent type 2 diabetes mellitus, they will be forced, due to the nature of the disease state, to prescribe more brand-name products for which therapeutic alternatives do not exist (i.e., glucometers, insulin, glucose testing strips, glucose testing lancets, insulin syringes) compared with an IPA that has a low volume of insulin-dependent type 2 diabetic patients. As previously noted, the ability to prescribe generic drugs depends on the availability of generic alternatives, but the availability of generic alternatives varies significantly as a function of case mix (i.e., as a function of patient and disease-related factors). ${ }^{9}$ A clearer understanding of the availability of generic alternatives for a given population would allow providers and payers to negotiate more rational financial incentives for generic prescribing. For incentives to be rational in the sense intended here, incentives must be based on the potential for generic substitution or therapeutic interchange within a medical group or IPA. Given the potential for differences in the ability of clinicians to substitute for alternatives (because of differences in case mix), uniform benchmarks, common in contemporary contracts between providers and payers, are inappropriate.

To date, insufficient research exists regarding the extent of variance in opportunities for generic prescribing. No one has quantified, for example, what proportion of drugs are available as generic or have a therapeutic alternative among medications used often in common medically treated chronic conditions such as diabetes, hypertension, and chronic respiratory diseases such as chronic obstructive pulmonary disease (COPD) and asthma. Examining variation in the availability of alternative generic drugs would provide insight to payers who create fixed GDR benchmarks for contracted IPAs, ACOs, and individual physicians based on internally derived formulas. We provide relatively simple mechanisms for quantifying the extent of generic substitution possible based on commonly available information in prescription claims data. Although this is an inexact science, such information should allow incentive benchmarks to be adjusted, leveling the playing field and providing equal opportunity for provider groups to achieve benchmarks when generic alternatives are available. Rational incentives should not penalize providers' use of branded products when no clinically acceptable generic substitute or generic therapeutic alternative is available to treat a patient's condition.
The purpose of this study was to define and measure, based on prescription claims data, the generic conversion potential of medication therapy of a midsized academic medical group. Medications that cannot be converted to generic alternative were also characterized by the reason for the inability to produce a generic conversion.

\section{Methods}

This study focused on identifying branded drugs being used when there were available alternatives of clinically appropriate generic drugs based on a retrospective analysis of prescription claims data from January 1, 2012, through December 31, 2012. Drugs in the claims data were classified based on an algorithm for coding medications as substitutable or not, which is described in further detail below. For illustrative purposes, drugs were further examined across groups of drugs known to be used in treating 4 common chronic diseases (see Table 1) as follows: hypertension, diabetes mellitus, COPD, and asthma. The groups of drugs were then characterized in terms of the proportion of medications that could be generic, as well as the burden that unavoidable branded medications for these diseases put on the overall GDR. Due to the large overlap of identical inhaled treatment options between COPD and asthma (i.e., Advair Diskus is a brand-only inhaled medication used for the treatment of COPD and asthma), these 2 disease states were subsequently combined and analyzed as 1 group. In addition, a descriptive measure of potential generic use within a disease, called the maximum generic rate (MGR), was constructed and analyzed.

The prescription data represented patients covered by a single pharmacy benefit manager (PBM). The physician group was composed of 3 large academic clinics: General Internal Medicine, Family Medicine, and Pediatrics, along with multiple community clinics including a federally qualified health center. The patients were racially diverse with significant numbers of African-American, Caucasian, and Hispanic patients. The insurance was not a Medicare plan, so the age distribution was younger than a cohort of all patients. Since all the patients were covered by insurance, indigent patients were not represented in the cohort. The analyses were based on the number of prescriptions for all medications or supplies.

Branded medications were coded as potentially substitutable (having an available therapeutically equivalent generic or available therapeutic alternative) or not potentially generic (no available therapeutically equivalent generic and no available therapeutic alternative that is nonbranded). The characterization was performed by one of the authors, who is a general internist and the chair of the medical center's pharmacy and therapeutics committee, and another author, who is a fellowship-trained ambulatory care clinical pharmacist, using the following algorithm (see Figure 1):

1. Was the medication a branded form of the same chemical entity that is available as a generic with the same delivery system? If yes, the medication was considered a potentially substitutable generic prescription. For instance, if Lipitor was prescribed and filled as the brand name product, it is considered potentially substitutable, since atorvastatin calcium is an available nonbranded, therapeutically equivalent medication. 


\section{TABLE 1 Medications Assigned to COPD/Asthma, Hypertension, and Diabetes}

\begin{tabular}{|c|c|c|c|c|c|}
\hline $\mathrm{H}$ & acebutolol & $\mathrm{H}$ & hydrochlorothiazide-methyldopa & $\mathrm{DM}$ & glyburide-metformin \\
\hline $\mathrm{H}$ & alfuzosin & $\mathrm{H}$ & hydrochlorothiazide-metoprolol & $\mathrm{DM}$ & insulin aspart \\
\hline $\mathrm{H}$ & aliskiren/amlodipine/hydrochlorothiazide & $\mathrm{H}$ & hydrochlorothiazide-moexipril & DM & insulin aspart protamine \\
\hline $\mathrm{H}$ & aliskiren-amlodipine & $\mathrm{H}$ & hydrochlorothiazide-olmesartan & DM & insulin aspart-insulin aspart protamine \\
\hline $\mathrm{H}$ & aliskiren-hydrochlorothiazide & $\mathrm{H}$ & hydrochlorothiazide-propranolol & $\mathrm{DM}$ & insulin detemir \\
\hline $\mathrm{H}$ & aliskiren-valsartan & $\mathrm{H}$ & hydrochlorothiazide-quinapril & DM & insulin glargine \\
\hline $\mathrm{H}$ & amiloride-hydrochlorothiazide & $\mathrm{H}$ & hydrochlorothiazide-spironolactone & $\mathrm{DM}$ & insulin glulisine \\
\hline $\mathrm{H}$ & amlodipine & $\mathrm{H}$ & hydrochlorothiazide-telmisartan & DM & insulin isophane \\
\hline $\mathrm{H}$ & amlodipine/hydrochlorothiazide/olmesartan & $\mathrm{H}$ & hydrochlorothiazide-triamterene & $\mathrm{DM}$ & insulin isophane-insulin regular \\
\hline $\mathrm{H}$ & amlodipine/hydrochlorothiazide/valsartan & $\mathrm{H}$ & hydrochlorothiazide-valsartan & $\mathrm{DM}$ & insulin lispro \\
\hline $\mathrm{H}$ & amlodipine-atorvastatin & $\mathrm{H}$ & irbesartan & $\mathrm{DM}$ & insulin lispro-insulin lispro protamine \\
\hline $\mathrm{H}$ & amlodipine-benazepril & $\mathrm{H}$ & isradipine & $\mathrm{DM}$ & insulin regular \\
\hline $\mathrm{H}$ & amlodipine-olmesartan & $\mathrm{H}$ & labetalol & $\mathrm{DM}$ & linagliptin \\
\hline $\mathrm{H}$ & amlodipine-telmisartan & $\mathrm{H}$ & lisinopril & $\mathrm{DM}$ & linagliptin-metformin \\
\hline $\mathrm{H}$ & amlodipine-valsartan & $\mathrm{H}$ & losartan & $\mathrm{DM}$ & metformin \\
\hline $\mathrm{H}$ & atenolol & $\mathrm{H}$ & methyclothiazide & $\mathrm{DM}$ & metformin-pioglitazone \\
\hline $\mathrm{H}$ & atenolol-chlorthalidone & $\mathrm{H}$ & methyldopa & $\mathrm{DM}$ & metformin-rosiglitazone \\
\hline $\mathrm{H}$ & azilsartan & $\mathrm{H}$ & metoprolol & $\mathrm{DM}$ & metformin-saxagliptin \\
\hline $\mathrm{H}$ & azilsartan-chlorthalidone & & minoxidil & $\mathrm{DM}$ & metformin-sitagliptin \\
\hline $\mathrm{H}$ & benazepril & $\mathrm{H}$ & moexipril & $\mathrm{DM}$ & nateglinide \\
\hline $\mathrm{H}$ & benazepril-hydrochlorothiazide & $\mathrm{H}$ & nadolol & $\mathrm{DM}$ & pioglitazone \\
\hline $\mathrm{H}$ & bendroflumethiazide & $\mathrm{H}$ & nicardipine & DM & repaglinide \\
\hline $\mathrm{H}$ & bendroflumethiazide-nadolol & $\mathrm{H}$ & NIFEdipine & $\mathrm{DM}$ & rosiglitazone \\
\hline $\mathrm{H}$ & betaxolol & $\mathrm{H}$ & nisoldipine & $\mathrm{DM}$ & saxagliptin \\
\hline $\mathrm{H}$ & bisoprolol & $\mathrm{H}$ & olmesartan & $\mathrm{DM}$ & simvastatin-sitagliptin \\
\hline $\mathrm{H}$ & bisoprolol-hydrochlorothiazide & $\mathrm{H}$ & perindopril & $\mathrm{DM}$ & sitagliptin \\
\hline $\mathrm{H}$ & candesartan & $\mathrm{H}$ & pindolol & $\mathrm{C} / \mathrm{A}$ & albuterol \\
\hline $\mathrm{H}$ & candesartan-hydrochlorothiazide & $\mathrm{H}$ & prazosin & $\mathrm{C} / \mathrm{A}$ & albuterol-ipratropium \\
\hline $\mathrm{H}$ & captopril & $\mathrm{H}$ & propranolol & $\mathrm{C} / \mathrm{A}$ & arformoterol \\
\hline $\mathrm{H}$ & captopril-hydrochlorothiazide & $\mathrm{H}$ & quinapril & $\mathrm{C} / \mathrm{A}$ & beclomethasone \\
\hline $\mathrm{H}$ & chlorothiazide & $\mathrm{H}$ & ramipril & $\mathrm{C} / \mathrm{A}$ & budesonide \\
\hline $\mathrm{H}$ & clonidine & $\mathrm{H}$ & telmisartan & $\mathrm{C} / \mathrm{A}$ & budesonide-formoterol \\
\hline $\mathrm{H}$ & diltiazem & $\mathrm{H}$ & terazosin & $\mathrm{C} / \mathrm{A}$ & ciclesonide \\
\hline $\mathrm{H}$ & doxazosin & $\mathrm{H}$ & timolol & $\mathrm{C} / \mathrm{A}$ & flunisolide \\
\hline $\mathrm{H}$ & enalapril & $\mathrm{H}$ & trandolapril & $\mathrm{C} / \mathrm{A}$ & fluticasone \\
\hline $\mathrm{H}$ & enalapril-hydrochlorothiazide & $\mathrm{H}$ & trandolapril-verapamil & $\mathrm{C} / \mathrm{A}$ & fluticasone-salmeterol \\
\hline $\mathrm{H}$ & eprosartan & $\mathrm{H}$ & triamterene & $\mathrm{C} / \mathrm{A}$ & formoterol \\
\hline $\mathrm{H}$ & eprosartan-hydrochlorothiazide & $\mathrm{H}$ & valsartan & $\mathrm{C} / \mathrm{A}$ & formoterol-mometasone \\
\hline $\mathrm{H}$ & felodipine & $\mathrm{H}$ & verapamil & $\mathrm{C} / \mathrm{A}$ & indacaterol \\
\hline $\mathrm{H}$ & fosinopril & $\mathrm{DM}$ & chlorpropamide & $\mathrm{C} / \mathrm{A}$ & ipratropium \\
\hline $\mathrm{H}$ & fosinopril-hydrochlorothiazide & $\mathrm{DM}$ & exenatide & $\mathrm{C} / \mathrm{A}$ & levalbuterol \\
\hline $\mathrm{H}$ & hydrALAZINE & $\mathrm{DM}$ & glimepiride-pioglitazone & $\mathrm{C} / \mathrm{A}$ & mometasone \\
\hline $\mathrm{H}$ & hydrALAZINE-hydrochlorothiazide & $\mathrm{DM}$ & glimepiride-rosiglitazone & $\mathrm{C} / \mathrm{A}$ & montelukast \\
\hline $\mathrm{H}$ & hydrochlorothiazide & $\mathrm{DM}$ & glipizide & $\mathrm{C} / \mathrm{A}$ & pirbuterol \\
\hline $\mathrm{H}$ & hydrochlorothiazide-irbesartan & $\mathrm{DM}$ & glipizide-metformin & $\mathrm{C} / \mathrm{A}$ & salmeterol \\
\hline $\mathrm{H}$ & hydrochlorothiazide-lisinopril & $\mathrm{DM}$ & glyburide & $\mathrm{C} / \mathrm{A}$ & tiotropium \\
\hline $\mathrm{H}$ & hydrochlorothiazide-losartan & & & & \\
\hline
\end{tabular}

2. Exceptions were made for NTI agents as defined in the 1988 NTI list from the U.S. Food and Drug Administration (FDA). ${ }^{13}$ An example is Dilantin. We also used more recent lists from Health Canada and the North Carolina Board of Pharmacy to produce the final NTI list: aminophylline carbamazepine, cyclosporine, digoxin, ethosuximide flecainide, levothyroxine sodium, lithium carbonate, phenytoin, primidone, procainamide hydrochloride, quinidine, sirolimus, tacrolimus, theophylline, valproic acid, and warfarin sodium. ${ }^{14,15}$ Medications that did not meet the first criterion were considered not potentially substitutable if they were in 1 of the 6 protected classes of drugs as defined in the 


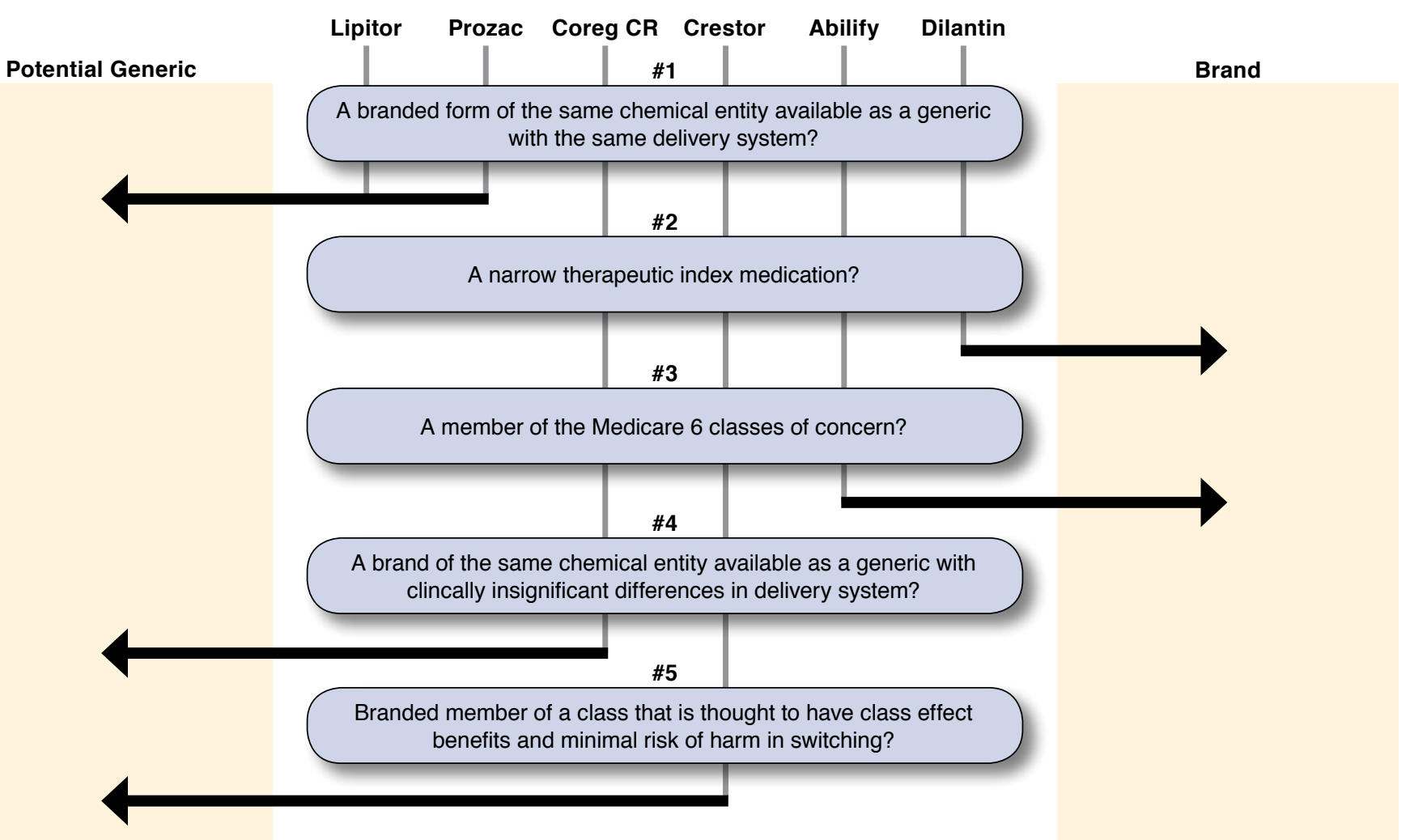

Medicare D provisions. ${ }^{17}$ These include immunosuppressant, antidepressant, antipsychotic, anticonvulsant, antiretroviral, and antineoplastic classes. For example, Abilify does not have a generic and is an antipsychotic.

3. For medications that were not NTI, or in 1 of the 6 protected classes, it was next determined if the medication was a branded form of the same chemical entity available as a generic product with a delivery system that differed from the branded drug in clinically insignificant ways, for example, Coreg CR. A switch from a daily to a twice daily regimen was considered acceptable (i.e., a therapeutic alternative), but conversion to a 3 or more times a day drug was not considered acceptable due to the increased risk of nonadherence. ${ }^{17-19}$

4. For medications still remaining, the reviewer determined if the medication was a branded member of a class that is thought clinically to have class effect benefits and minimal risk of harm in switching (i.e., a therapeutic alternative). For example, the use of brand-only Crestor $10 \mathrm{mg}$ for the treatment of hyperlipidemia. This would be considered a potentially generic prescription due to the availability of generic atorvastatin calcium at higher, equipotent doses.

This algorithm required clinical judgment. Two independent coders coded each drug and had zero disagreements.
All medications and prescriptions were categorized for further analysis according to the reason for nonsubstitutability: NTI; 6 protected classes; branded durable medical equipment, supply, or device; and unnecessary branded formulation. For illustrative purposes, medications were selected and categorized further as being predominantly indicated for diabetes (DM), hypertension (HTN), or COPD/asthma (see Table 1).

MGR was defined as the highest proportion of generic medication use possible.

Maximum Generic Rate: 1 - not potentially substitutable rate

Another useful concept employed was the brand burden of a disease. This is the not potentially substitutable rate for a specific disease or, more specifically, for the set of prescriptions inferred to be used for the disease in our analysis. So for either a disease or, in our case, a group of medications inferred to be for a disease, we defined the following:

Brand Burden $_{\text {(disease) }}=1-$ Maximum Generic Rate $_{\text {(disease) }}$

The brand burden was determined for the diseases HTN, $\mathrm{DM}$, and COPD/asthma.

\section{Results}

There were 99,336 prescriptions or supplies filled during 1 year of observation, with $76.1 \%$ being generic. Table 2 shows 
A Case Study in Generic Drug Use: Should There Be Risk Adjustment in Incentive Payments for the Use of Generic Medications?

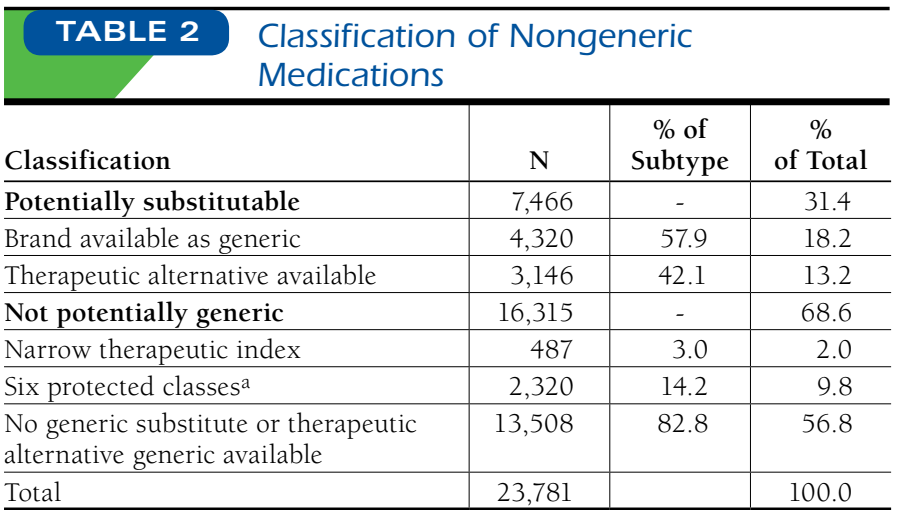

asix protected classes include immunosuppressants, antidepressants, antipsychotics, anticonvulsants, antiretrovirals, and antineoplastics.

the classification of the 23,781 nongeneric prescriptions into 5 mutually exclusive types. More than two-thirds (68.6\%) of the prescriptions were classified as not potentially generic. The inclusion of medications from the 6 protected drug classes only contributed to $9.8 \%$ of the nongeneric prescriptions, with the inclusion of NTI medication being less at $2.0 \%$. The majority of branded products were prescribed in clinical contexts where there was no generic alternative available. The majority of the potentially generic prescriptions were found to be for branded versions of generically available medications.

The distribution across disease categories of the brand-only medications and durable medical equipment and supplies is shown in Table 3. DM (30.9\%) and COPD/asthma (23.1\%) accounted for more than half of the prescriptions that could not be switched to a generic alternative. Roughly 1 in 8 of the prescriptions were for supplies used for the treatment of DM (e.g., syringes, test strips, etc.). The largest single category included medications used to treat diseases other than DM or COPD/ asthma. This category contained no prescriptions for drugs used to treat HTN. The 6 protected classes from Medicare Part D, combined with NTI drugs, accounted for roughly 15\% of prescriptions that could not clinically appropriately be written for generic alternatives.

Table 4 shows potential generic substitutability (generic, potentially substitutable, or not potentially substitutable) overall and by the selected disease categories (HTN, DM, COPD/ asthma). Table 4 also includes the MGR overall and by selected disease category. Potentially substitutable branded prescribing was highest for COPD/asthma at $14.7 \%$ and lowest for DM at $3.0 \%$. The average for all prescriptions was $7.5 \%$. The not potentially substitutable rate was $16.4 \%$ overall. The specific not potentially substitutable rate for each disease, or brand burden, was as high as $73 \%$ for COPD/asthma and 0\% for HTN. The MGRs ranged from $100 \%$ for HTN to $26.7 \%$ for COPD/asthma, while the average for all prescriptions was $83.6 \%$.

\section{Discussion}

Generic substitution remains a valuable tool in improving efficiency in the health care system. However, our findings illus-

\begin{tabular}{l|c}
\hline TABLE 3 & $\begin{array}{c}\text { Distribution of Branded-Only } \\
\text { Medications and DME by Disease Type }\end{array}$ \\
\hline Drug Category & $\begin{array}{c}\text { Percentage of Branded-Only } \\
\text { Medications or Equipment }\end{array}$ \\
\hline DM & $30.9 \%$ (13.3\% DME, 17.6\% medications) \\
\hline COPD/asthma & $23.1 \%$ \\
\hline Medications for other diagnoses & $31 \%$ \\
\hline Six protected classes & $11.6 \%$ \\
\hline Narrow therapeutic index & $2.9 \%$ \\
\hline Non-DM DME & $0.5 \%$ \\
\hline COPD =chronic obstructive pulmonary disease; DM=diabetes mellitus; \\
DME=durable medical equipment.
\end{tabular}

trate the importance of considering the underlying distribution of drugs, itself impacted by underlying case mix, in the formation of policy surrounding generic drug use. This is of particular concern if strong financial incentives are tied to achieving fixed benchmarks. Failure to adjust can lead to perverse incentives that may encourage institutions either to select patients whose drug therapy can be handled exclusively by generics (e.g., HTN) and/or to provide less than optimal clinical care by prescribing generic drugs when a branded alternative would be the true drug of choice.

This project attempts to address the question of how to set an optimal target for generic drug use. Here, we offer a relatively low cost method inferred from the existing prescribing data. Adjustment along these lines at an institutional or IPA level would promote feasible generic substitution but not penalize groups that had a disadvantageous patient mix (e.g., groups with large numbers of patients with COPD/asthma and/or DM) or incentivize inappropriate medication switching when the drug is unavailable as a generic.

There are other ways to perform a case mix adjustment. For example, one might use financial claims data to determine the mix of diseases in a given cohort of patients. Each disease could have an ideal MGR, and across all diseases, an overall weighted MGR could be developed. Our data suggest sizable differences in the maximum feasible generic prescribing rate by disease, with asthma and other chronic obstructive lung diseases having an MGR a quarter of that of HTN, $26.7 \%$ vs. $100 \%$.

Although this method of case adjustment is what is often done for length of stay, cost of care, and other markers, we believe the better method is to determine, for each medication, whether there was a potentially acceptable generic substitute or therapeutic alternative available as a generic, as we have done. In this manner, imperfect knowledge of the diseases and the best MGR for each disease is not required. In addition, the development of the MGR allows an assignment of each branded medication as having a clinically acceptable generic substitute or generic therapeutic alternative or not, something that can be shared with prescribers.

Initially, making this determination for each medication is not trivial, but once performed, maintenance of this database would require changes only for newly available generic formulations, newly available medications and new evidence-based 
A Case Study in Generic Drug Use: Should There Be Risk Adjustment in Incentive Payments for the Use of Generic Medications?

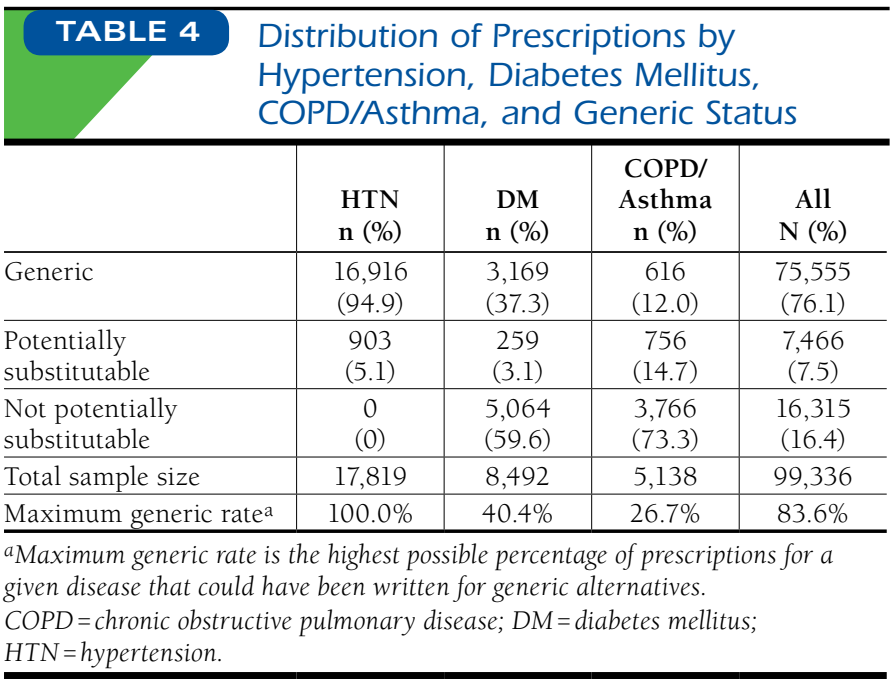

indications, whether FDA approved or off-label. Further, as electronic medical records capture better and better data, if shared with PBMs, this type of model can always be improved.

One of the remarkable findings was the large differences in the brand burden by disease. This is clearly related to factors that will change over time, such as the guideline-based preferred therapy for a disease and new evidence-based brand-only additions to therapy and generic availability. In addition, the particular order of medication given for a chronic disease in a patient over time may affect the use of generic medications. Nonetheless, the concept of a brand burden for a disease becomes clear when looking at our 3 diseases of interest. In our cohort, HTN has no brand burden. Treating HTN pharmacologically or taking new patients with HTN into an IPA should not affect nongeneric medication use if medications are selected carefully.

On the other hand, DM has a large brand burden. Moreover, for patients on insulin, not only the insulin itself but also the syringes, lancets, test strips, and glucometers produce multiple branded prescriptions with no generic alternatives. Consequently, a traditional fixed generic rate incentive would produce a misaligned incentive not to use insulin. Ideally, there should be no incentive in place that would lead prescribers to consider delaying the start of insulin therapy. For diseases such as asthma and COPD, most medical therapy is also presently branded, and the brand burden we found was $73.3 \%$. Here, clinicians should not be disincentivized to diagnose lung disease or treat with branded inhalers, since this, in fact, would represent the best clinical, evidence-based practice.

Using the concept of the MGR, the performance of an IPA, clinician, or health system would be based on the difference between their MGRs and their actual generic rates. In the example analyzed in this article, the medical therapy for HTN is not ideal. While the MGR is $100 \%$, the actual generic rate is $94.9 \%$, and there is still a 5\% improvement that can be made within drugs used to treat this common disease. Overall, the MGR is $83.6 \%$, and the actual generic rate is $76.1 \%$, so it follows that the incentive should be to move from $76.1 \%$ to $83.6 \%$ by better use of generic medications. Moreover, if the MGR is used, there are no incentives to decrease the proportion of patients with DM, asthma, and COPD or to cut down on insulin or inhaler use.

\section{Limitations}

The physician group used for this study is predominantly urban within an academic teaching center. Prescribing decisions may not represent the norm for IPAs as a whole. Patient population is also limited to a commercially insured health maintenance organization population in a large urban setting. It is not likely representative of the average patient who has medication therapy managed by a PBM, which now may encompass Medicaid, Medicare, and commercial insurers.

There are inherent limitations in our coding of drugs based solely on prescription claims data. First, there is potential for error via the underlying assumptions that a medication is being used for a specific indication without patient-level information. However, this might not be such a significant weakness, since often a generic substitution exists, independent of the exact indication. For instance, whether the use of a branded angiotensin receptor blocker is for nephropathy, heart failure, or HTN, an acceptable generic substitution is available. This is likely more often the case than the presence of a generic substitution only being available for one indication but not another. Again, in practical use of this method, periodic clinical updating of whether or not a drug has a generic substitute would be helpful and recommended.

Second, in this analysis, we chose to use a somewhat arbitrary NTI list because the FDA has not produced a recent NTI list, and there are many to choose from. Hence, we included a medication such as levothyroxine as an NTI medication, but a more aggressive PBM may have left this out. The same could be said for the 6 protected classes used in Medicare D formularies. The exclusion of NTI and protected classes of medications contributed to about 1 in 6 of the not potentially substitutable prescriptions. Thus, it is clear that if others use our method and produce an MGR for a disease or cohort of patients, the results are likely to change some, but the MGR method will be consistent across the prescribers and IPAs being managed for a given PBM.

Third, the method requires clinical judgment, and we based our results on consensus between only 2 experienced clinicians. Although we recognize that this is imperfect in design and that the number of clinicians involved in decision making was low, we felt it was sufficient for the purpose of introducing the concept. Further, the general method used here is relatively easily adapted to other settings, and if a PBM were to adopt this methodology, it could certainly choose to use more than 2 clinicians.

\section{Conclusions}

Substantial efficiencies can be gained by substituting generic drugs for branded drugs, but this can only be done when the drugs used for a particular condition are actually available in clinically acceptable generic form. The availability of generic alternatives varies substantially across prescriptions currently 
being used. To illustrate, essentially all drugs for HTN are available as generic, or have a generic alternative, but most drugs for obstructive lung disease do not have a generic alternative. Hence, the maximum rate of generic substitution is determined by the underlying patient population. Because incentives ignore drug and disease-specific variation in the availability of generic alternatives, continued use of uniform generic prescription incentive rates may encourage patient cherry-picking or inappropriate prescribing. Rational incentives for generic drug use should vary according to the underlying patient case-mix. As a solution, we proposed using a per medication methodology and determining an MGR.

\section{Authors}

SURREY M. WALTON, PhD, is Associate Professor, Department of Pharmacy Systems, Outcomes, and Policy, and CHRISTINE RASH, PharmD, is Clinical Pharmacist and Internal Medicinel Managed Care Clinical Assistant Professor, Department of Pharmacy Practice, College of Pharmacy, University of Illinois Chicago. BRUCE L. LAMBERT, PhD, is Professor, Department of Communication Studies, and Director, Center for Education and Research on Therapeutics, Northwestern University, Chicago, Illinois, and WILLIAM L. GALANTER, MD, PHD, is Assistant Professor, Departments of Medicine; Pharmacy Practice; and Pharmacy Systems, Outcomes, and Policy, University of Illinois Chicago, and Medical Director, Center for Education and Research on Therapeutics, Northwestern University, Chicago, Illinois.

AUTHOR CORRESPONDENCE: Surrey M. Walton, PhD, Department of Pharmacy Systems, Outcomes, and Policy, College of Pharmacy, University of Illinois Chicago, $833 \mathrm{~S}$. Wood St., (M/C 871) Rm. 287, Chicago IL 60612. Tel.: 312.413.2775;

E-mail:walton@uic.edu.

\section{DISCLOSURES}

None of the authors received any funding directly for this study; however, Galanter and Lambert are supported by grant number U19HS021093 from the Agency for Healthcare Research and Quality. The content is solely the responsibility of the authors and does not necessarily represent the official views of the Agency for Healthcare Research and Quality. The funders had no role in study design, data collection and analysis, decision to publish, or preparation of the manuscript.

Study concept and design were primarily contributed by Galanter, Walton, and Lambert, with assistance from Rash. Rash and Galanter collected the data, which was interpreted by Walton, Rash, and Galanter, with assistance from Lambert. The manuscript was written by Walton, Lambert, Rash, and Galanter and revised by Rash, Galanter, Walton, and Lambert.

\section{REFERENCES}

1. Duru OK, Ettner S, Turk N, et al. Potential savings associated with drug substitution in Medicare Part D: the Translating Research into Action for Diabetes (TRIAD) Study. J Gen Intern Med. 2014;2(1):230-36.

2. Aitken M, Berndt ER, Cutler DM. Prescription drug spending trends in the United States: looking beyond the turning point. Health Aff (Millwood). 2009;28(1):wl51-wl60.
3. Balaban D, Dhalla I, Law M, Bell C. Private expenditures on brand name prescription drugs after generic entry. Appl Health Econ Health Policy. 2013;11(5):523-29.

4. Gilman BH, Kautter J. Impact of multitiered copayments on the use and cost of prescription drugs among Medicare beneficiaries. Health Serv Res. 2008;43(2):478-95.

5. Hartman M, Martin A, Nuccio O, Catlin A; National Health Expenditure Accounts Team. Health spending growth at a historic low in 2008. Health Aff (Millwood). 2010;29(1):147-55.

6. Martin AB, Hartman M, Whittle L, Catlin A; National Health Expenditure Accounts Team. National health spending in 2012: rate of health spending growth remained low for the fourth consecutive year. Health Aff (Millwood). 2014;33(1):67-77.

7. Share DA, Mason MH. Michigan's Physician Group Incentive Program offers a regional model for incremental 'fee for value' payment reform. Health Aff (Millwood). 2012;31(9):1993-2001.

8. Conrad DA, Perry L. Quality-based financial incentives in health care: can we improve quality by paying for it? Annu Rev Public Health. 2009;30(1):357-71.

9. Wosinska M, Huckman RS. Generic dispensing and substitution in mail and retail pharmacies. Health Aff (Millwood). 2004;Suppl Web Exclusives:W4-409-16.

10. Kunisawa S, Otsubo T, Lee J, Imanaka Y. Improving the assessment of prescribing: use of a 'substitution index'. J Health Serv Res Policy. 2013;18(3):138-43.

11. Dylst P, Vulto A, Simoens S. Demand-side policies to encourage the use of generic medicines: an overview. Expert Rev Pharmacoecon Outcomes Res. 2013;13(1):59-72.

12. Hoadley JF, Merrell K, Hargrave E, Summer L. In Medicare Part D plans, low or zero copays and other features to encourage the use of generic statins work, could save billions. Health Aff (Millwood). 2012;31(10):2266-75.

13. Center for Drug Evaluation and Research. Guidance for industry: bioavailability and bioequivalence studies for orally administered drug products_-general considerations. March 2003. Available at: http://www.fda.gov/ downloads/Drugs/GuidanceComplianceRegulatoryInformation/Guidances/ ucm070124.pdf. Accessed September 15, 2014.

14. North Carolina Department of Health and Human Services. North Carolina Medicaid Pharmacy Newsletter. Number 115, March 2004, page 6. Available at: http://www.ncdhhs.gov/dma/pharmnews/0304pharm.pdf. Accessed September 23, 2014.

15. Health Canada. Guidance document: comparative bioavailability standards: formulations used for systemic effects. Ottawa, Ontario. February 2012. Available at: http://www.hc-sc.gc.ca/dhp-mps/alt_formats/pdf/prodpharma/applic-demande/guide-ld/bio/gd_standards_ld_normes-eng.pdf. Accessed September 23, 2014.

16. U.S. Center for Medicare and Medicaid Services. Medicare prescription drug benefit manual. Chapter 6: Part D drugs and formulary requirements 2010. Available at: https://www.cms.gov/Medicare/Prescription-DrugCoverage/PrescriptionDrugCovContra/downloads/Chapter6.pdf. Accessed September 15, 2014.

17. Wells KE, Peterson EL, Ahmedani BK, Williams LK. Real-world effects of once vs greater daily inhaled corticosteroid dosing on medication adherence. Ann Allergy Asthma Immunol. 2013;111(3):216-20.

18. Coleman CI, Roberts MS, Sobieraj DM, Lee S, Alam T, Kaur R. Effect of dosing frequency on chronic cardiovascular disease medication adherence. Curr Med Res Opin. 2012;28(5):669-80.

19. Coleman CL, Limone B, Sobieraj DM, et al. Dosing frequency and medication adherence in chronic disease. J Manag Care Pharm. 2012;18(7):52739. Available at: http://www.amcp.org/WorkArea/DownloadAsset. aspx?id=15582. 